\title{
Cerebral Hemodynamics and Intracranial Compliance Impairment In Critically III COVID-19 Patients: A Pilot Study
}

Sérgio Brasil ( $\sim$ sbrasil@alumni.usp.br)

University of São Paulo https://orcid.org/0000-0003-2397-9947

Fabio Silvio TACCONE

Université Libre de Bruxelles: Universite Libre de Bruxelles

Sâmia Yasin WAHYS

University of São Paulo

Bruno Tomazini

University of São Paulo

Filippo ANNONI

Université Libre de Bruxelles: Universite Libre de Bruxelles

Sérgio FONSECA

University of São Paulo

Estevão BASSI

University of São Paulo

Bruno LUCENA

Universidade de São Paulo: Universidade de Sao Paulo

Ricardo de Carvalho Nogueira

University of São Paulo

Marcelo DE-LIMA-OLIVEIRA

University of São Paulo

Edson BOR-SENG-SHU

University of São PAulo

Wellingson Paiva

University of Sao Paulo

Alexis Fournier Turgeon

Université Laval

Manoel Jacobsen Teixeira

University of São Paulo

Luiz Marcelo Sá Malbouisson

University of São Paulo 
Research

Keywords: severe acute respiratory syndrome, COVID-19, cerebral hemodynamics, intracranial compliance, intracranial pressure, intracranial compliance, cerebrovascular resistance, cerebral perfusion pressure, COVID-19

Posted Date: December 14th, 2020

DOl: https://doi.org/10.21203/rs.3.rs-125420/v1

License: (c) (i) This work is licensed under a Creative Commons Attribution 4.0 International License. Read Full License 


\section{Abstract}

Introduction: One of the possible mechanisms by which the new coronavirus (SARS-Cov2) could induce brain damage is the impairment of cerebrovascular hemodynamics $(\mathrm{CVH})$ and intracranial compliance (ICC), due to the elevation of intracranial pressure (ICP). The main objective of this study was to assess the presence of $\mathrm{CVH}$ and ICC alterations in patients with COVID-19 and evaluate their association with short-term clinical outcome.

Methods: 50 consecutive critically ill COVID-19 patients were studied with transcranial Doppler (TCD) and a non-invasive monitoring of ICC. Subjects were included on ICU admission; $\mathrm{CVH}$ was evaluated using mean flow velocities in the middle cerebral arteries (mCBFV), pulsatility index (PI) and estimated cerebral perfusion pressure (eCPP), while ICC using the P2/P1 ratio of estimated ICP curve (B4C device). The primary composite outcome was unsuccessful weaning from respiratory support or death at day 7 .

Results: On the first assessment $(n=50)$, only P2/P1 (1.20 [1.00-1.28] vs. 1.00 [0.88-1.16]; $p=0.03)$ and elCP (14 [11-25] vs. 11 [7-15] mmHg; $p=0.01)$ were significantly higher among patients with UO than others. Patients with UO had a significantly higher $\mathrm{CVH} / \mathrm{ICC}$ score (9 [8-12] vs. 6 [5-7]; $p<0.001)$ than those with favorable outcome; the area under the receiver operating curve (AUROC) for $\mathrm{CVH} / \mathrm{ICC}$ score to predict UO was 0.86 (95\% Cls $0.75-0.97)$; a score $>8.5$ had 63 (46-77)\% sensitivity and 87 (62-97)\% specificity to predict UO. For those patients undergoing a second assessment $(n=29)$ after a median of 11 (5-31) days, all measured variables were similar between the two time-points. No differences in the measured variables between ICU non-survivors $(n=30)$ and survivors were observed.

Conclusions. ICCI and CVH disturbances are often present in COVID-19 severe illness and could accurately predict early poor outcome.

\section{Introduction}

The severity of the disease caused by the new coronavirus 2019 (COVID-19) is predominantly harbored in a severe acute hypoxemic respiratory failure, which often requires ventilatory support. However, the involvement of other organs, such as the central nervous system (CNS), heart, kidneys, intestines and testicles, ${ }^{1-6}$ has been reported. Neurological manifestations vary from acute cerebrovascular events to immuno-mediated disease, such as Guillain-Barre syndrome or cytotoxic lesion of the corpus callosum. ${ }^{7-}$

${ }^{9}$ Importantly, it remains still unclear whether CNS disorders are the consequences of the acute respiratory failure, of systemic aggressions, of the hypercoagulable status or to the primary CNS invasion from the virus. $^{10}$

As many COVID-19 patients experience neurological symptoms, such as headache, anosmia, paresthesia, nausea, vomiting and alteration of consciousness, ${ }^{11}$ one hypothesis could also be that intracranial compliance (ICC) and cerebrovascular hemodynamics (CVH) are impaired in the early course of the disease, either directly (i.e. encephalitis, edema or focal ischemia) or indirectly [i.e. hypoxic distress and 
endothelial dysfunction $]^{12}$. This would be even more frequent in critically ill patients, who suffer often from persistent somnolence, lethargy and delirium. ${ }^{13,14}$

Intracranial pressure (ICP) monitoring is the cornerstone in the clinical management of acute brain-injured patients at risk of intracranial hypertension $(\mathrm{ICH}) .{ }^{15}$ Still, this monitoring tool has a limited use outside neuro-critical settings, because of the invasive nature of the monitoring and its availability. ICH would result in altered ICC and, consequently, secondary brain damage. In COVID-19 patients, unless a structural damage with mass effect is documented on brain imaging, there is no indication to implant an ICP monitor; however, non-invasive techniques able to estimate CVH and/or ICP curves, ${ }^{16-18}$ may be helpful to understand changes in cerebral perfusion in this setting. ${ }^{19}$

The purpose of the study was to evaluate the relationship between $\mathrm{CVH}$ and ICC in a cohort of mechanically ventilated critically ill patients infected with SARS-CoV-2 on clinical outcomes.

\section{Methods}

\section{Study design}

We conducted a single center, observational and prospective study in 6 intensive care units (ICUs) of the Hospital das Clínicas, São Paulo university, Brazil, from May to June 2020. This cohort study protocol was registered on Clinicaltrials.gov (NCT04429477). All consecutive patients with confirmed COVID-19 by real-time reverse transcription-polymerase chain reaction positive testing were eligible within the first 72 hours since the initiation of invasive mechanical ventilation. Exclusion criteria included the absence of legally authorized responsible (LAR) consent, the absence of temporal acoustic window for TCD assessment, patients unable to undergo monitoring with the ICC monitoring due to lesions and/or skin infections in the sensor application region, patients with head circumference smaller than $47 \mathrm{~cm}$. The study protocol followed the Standards for Reporting of Diagnostic Accuracy Studies (STARD) statement (Supplemental Table 1), was approved by the local Ethics Committee, which required a signed consent from the next of kin before inclusion.

Eligible subjects were identified by the ICU teams (SYW, SF, BT, EB and LMSM). Two assessments of CVH and ICC were performed, one during the first 3 days since intubation and a second up to 72 hours after extubation or tracheotomy without administration of sedatives; for patients who died while intubated, only the first evaluation was considered. Clinical parameters, such as systemic arterial pressure, fluid balance, use of sedatives, $\mathrm{PaO}_{2}$ and $\mathrm{PaCO}_{2}$, hemoglobin and body temperature, were concomitantly recorded. One operator, without knowledge of the individual clinical features, performed all evaluations. Data on demographic characteristics, Simplified Acute Physiologic Score (SAPS) 3, use of intravenous sedatives, vasopressors and other physiological and laboratory data were also collected. Details on the monitoring techniques are shown in the Supplement Material.

\section{Intracranial compliance monitoring technique}


ICC was evaluated non-invasively by assessing cranial deformation using a specific device (B4C; Brain4care Corp., São Carlos, Brazil). The B4C sensor consists of a support for a sensor bar that detects local cranial bone deformations using specific sensors. The detection of these deformations is obtained by a cantilever bar modeled by finite element calculations. For this bar, voltage meters are attached for deformation detection. Non-invasive contact with the skull is obtained by adequate pressure directly into the scalp by means of a pin. The system is positioned in the frontotemporal region, around 3 centimeters over the first third of the orbitomeatal line, this way avoiding temporal superficial artery main branches and temporal muscle, providing contact of the sensor in an area of thin skin and skull, whereas slight pressure is applied on the adjustable band until optimal signal is detected.

Variations in ICP cause deformations in the cranial bone, which are detected by the sensor bar. The device filters, amplifies and scans the sensor signal and sends the data to a mobile device. The method is completely non-invasive and painless. In addition, it does not interfere with any routine monitoring. The waveform obtained is equivalent to ICP waveform obtained using invasive techniques, such intraparenchymal probes or external ventricular derivation, ${ }^{20}$ and the relation between its different components provides information on ICC. ${ }^{21}$ In particular, each cardiac beat corresponds to an ICP waveform composed of three peaks; arterial pulsation (P1); cerebral venous flow, which is secondary to cyclic fluctuations of arterial blood volume, reflecting intracranial compliance (P2); the aortic valve closure (P3; Fig. 1). ${ }^{22}$

The B4C analytics system verified all collected data by the sensor. ICP pulse waves morphology parameters such as the P2/P1 ratio. For this study, all calculations were performed using the mean pulse of the ICP, calculated by identifying and extracting all ICP pulses, excluding possible artifacts. The mean pulse was used to calculate the amplitudes of the P1 and P2 peaks, which were obtained by detecting the highest point of these peaks and subtracting the base value of the ICP pulse. The P2/P1 ratio was calculated by dividing the amplitude of these two points. In case of P2 > P1, ICC was defined as "abnormal".

\section{Cerebrovascular hemodynamics assessment}

Conventional transcranial Doppler [(TCD) EZ-DOP, DWL Compumetrics, Singen, Germany] was used to assess $\mathrm{CVH}^{23} \mathrm{~A}$ complete evaluation of right and left cerebral hemispheres and the brainstem arteries was performed prior to the study to discard focal stenosis, using Doppler colored technique with low frequency probe $(2 \mathrm{MHz})$ and scanning every $1 \mathrm{~mm}$ of arterial extension, through the temporal, orbital, suboccipital, retro-mastoid and submandibular windows. Hemodynamic parameters of interest were mean flow velocities in the middle cerebral arteries (mCBFV), peak systolic and final diastolic velocities, because the MCA supplies $80 \%$ of cerebral blood flow approximately. Abnormal mCBFV was identified by values $<40$ or $\geq 100 \mathrm{~cm} / \mathrm{sec}$. 
Using TCD, elevation of ICP was suspected when pulsatility index $(\mathrm{PI}) \geq 1.2$ (i.e. "abnormal" $\mathrm{PI}$ ). ${ }^{24,25} \mathrm{PI}$ was calculated by the following formula: $\mathrm{PI}=\mathrm{Sv}-\mathrm{Dv} / \mathrm{Mv}$ (Sv: systolic velocity, Dv: diastolic velocity and Mv: mean flow velocity). Moreover, TCD allows calculation of estimated CPP (eCPP) and ICP (elCP), ${ }^{25}$ which are significantly correlated with invasive ICP measurements. ${ }^{23,26}$ Abnormal elCP was considered if $>20 \mathrm{mmHg}$; abnormal eCPP if $\leq 45$ or $\geq 75 \mathrm{mmHg}$.

\section{Outcomes}

As a wide range of variables are involved in the prognosis of COVID-19, ${ }^{27-30}$ we limited our analyses to the prevalence and predictive values of ICC and CVH disturbances on early unfavorable outcome (UO); UO was a composite end-point including either absence of weaning from mechanical ventilation (MV) or death at day 7 after inclusion in the study.

$\mathrm{CVH}$ and ICC impairment were identified using the different combination of TCD and B4C values; in particular, P2/P1 ratio, $\mathrm{mCBFV}$, elCP, PI and eCPP were categorized and an arbitrary score was developed to describe different degree of these alterations (Table 1). For each variable, severity was defined by a $\mathrm{CVH} / \mathrm{ICC}$ score from 1 until 4 . As such, the sum of the severity score for each variable gave a score ranging from a minimum of 5 to a maximum of 20. The score was then classified as: "normal", i.e. 5 points, which suggested no abnormalities; "mild CVH/ICC abnormalities", i.e. 6 to 7 points, which was associated with minor disturbances in one or two variables; "moderate $\mathrm{CVH} / \mathrm{ICC}$ abnormalities", i.e. 8 to 9 points; "severe $\mathrm{CVH} / \mathrm{ICC}$ impairment", i.e. $\geq 10$ points.

Table 1

Thresholds for P2/P1 ratio, mCBFV, PI, elCP and eCPP. Progressive points were in accordance with the worst results. $\mathrm{CVH} / \mathrm{ICCl}$ : cerebrovascular hemodynamics and intracranial compliance impairment, mCBFV: middle cerebral artery highest mean velocity; elCP: estimated intracranial pressure; eCPP: estimated cerebral perfusion pressure.

\begin{tabular}{|lllllll|}
\hline Points & P2/P1 & mCBFV & PI & eICP & elCP & Score (sum of each) \\
\hline 1 & $\leq 1$ & 40 to 70 & $<1.2$ & $<15$ & 50 to 75 & 5 no $\mathrm{CVH} / \mathrm{ICCl}$ \\
\hline 2 & 1.01 to 1.19 & 71 to 99 & $\geq 1.2$ & $15-20$ & $\geq 75$ & $6-7$ mild $\mathrm{CVH} / \mathrm{ICCl}$ \\
\hline 3 & $\geq 1.2$ & $\geq 100$ & $\geq 1.3$ & $21-25$ & $\leq 50$ & $8-9$ moderate $\mathrm{CVH} / \mathrm{ICCl}$ \\
\hline 4 & $\geq 1.4$ & $<40$ & $\geq 1.4$ & $>25$ & $<40$ & $\geq 10$ severe $\mathrm{CVH} / \mathrm{ICCl}$ \\
\hline
\end{tabular}

\section{Sample size}

Due to the lack of clinical reports in this field, this research should be considered a pilot study. Using the upper confidence interval for the population variance approach to the sample size calculation, a pilot sample size between 20 and 40 was chosen, corresponding to standardized effect sizes of 0.4 and 0.7 (for $90 \%$ power based on a standard sample size calculation) ${ }^{31}$. Thus, considering the risk for early deaths and lack of second TCD and B4C assessment, 50 patients were enrolled to test our hypothesis.

\section{Statistical analysis}


Descriptive statistics were computed for all study variables. Categorical variables are presented as count $(\%)$, while continuous variables are presented as mean ( \pm standard deviation) or median (25th -75 th percentiles), according to their distribution. Differences between groups (i.e. UO vs favorable outcome; non-survivors vs. survivors) were assessed using a $\chi$-square or Fisher's exact test for categorical variables, t-Student test for normally distributed continuous variables and Mann-Whitney or KruskalWallis tests for asymmetrically distributed continuous variables. Differences between the first and second assessment were assessed using a Wilcoxon paired test. The discriminative ability of each variable (i.e. $\mathrm{P} 2 / \mathrm{P} 1, \mathrm{mCBFV}, \mathrm{PI}, \mathrm{eICP}$ and eCPP) with significant difference between $\mathrm{UO}$ and favorable outcome was evaluated to predict $\mathrm{UO}$, using receiver operating characteristic $(\mathrm{ROC})$ curves with the corresponding area under the curve (AUROC). Youden's index was computed to assess the optimal predictive cut-off. A $p<$ 0.05 was considered as statistically significant. All analyses were performed using the AcaStat software version 2200.5.2 (USA, available at www.acastat.com).

\section{Results}

\section{Study population}

Between May and June 2020, 2813 patients with COVID-19 were admitted at our institution. Among those, 1579 were admitted in ICU and 552 critically ill patients died (35\%). A total of 50 consecutive patients were eventually included within 72 hours from ICU admission. Characteristics of the study population are shown in Table 2. On day 7 from inclusion into the study, $31(62 \%)$ were still on MV and 4 (8\%) have died, resulting in $35(70 \%)$ with UO. After a median of 11 (5-31) days, 29 patients (18 of those still required intermittent non-invasive ventilation) were weaned from MV and underwent a second $\mathrm{CVH} / \mathrm{ICC}$ assessment. At ICU discharge, 2 of the 15 patients with FO on day 7 had died; 24 out of the 31 alive on day 7 but still on MV (UO) eventually died during the ICU stay. As such, ICU mortality was observed in 30 (60\%) patients (Table 2$)$. 
Table 2

Clinical characteristics of patients with COVID-19, according to the occurrence of the primary outcome (FO: favorable outcome, UO: unfavorable outcome).

\begin{tabular}{|c|c|c|c|c|c|}
\hline Characteristic & $\begin{array}{l}\text { Total } \\
(\mathrm{N}=50)\end{array}$ & $\begin{array}{l}\text { FO } \\
(N=15)\end{array}$ & $\begin{array}{l}\text { UO } \\
(N=35)\end{array}$ & $\begin{array}{l}\text { Survivors } \\
(\mathrm{N}=20)\end{array}$ & $\begin{array}{l}\text { Non- } \\
\text { survivors } \\
(\mathrm{N}=30)\end{array}$ \\
\hline Age, median (IQR) - years & $62(44-68)$ & $38(17-63)$ & $64(49-68)$ & $49(17-63)$ & $66(51-68)$ \\
\hline Female gender - no. (\%) & 44 & 48 & 43 & 42.9 & 44.8 \\
\hline SAPS 3, median (IQR) & $63(52-75)$ & $55(51-72)$ & $69(57-78)$ & $58(51-69)$ & $67(54-78)$ \\
\hline Antibiotics use - no. (\%) & $36(76.6)$ & $14(70.2)$ & $22(82)$ & $15(71.4)$ & $21(80.8)$ \\
\hline \multicolumn{6}{|l|}{$\begin{array}{l}\text { Comorbidities and risk } \\
\text { factors - no. (\%) }\end{array}$} \\
\hline Hypertension & $26(54.2)$ & $9(50)$ & $17(53)$ & $11(52.4)$ & $15(55.6)$ \\
\hline Diabetes & $15(31.2)$ & $6(33)$ & $9(28)$ & $6(28.6)$ & 9 (33.3) \\
\hline Obesity & $20(42.5)$ & $10(55)$ & $10(31)$ & $9(42.9)$ & $11(42.3)$ \\
\hline Current smoker & 15 (31.2) & $5(27)$ & $10(31)$ & $6(28.6)$ & $9(33.3)$ \\
\hline Chronic kidney failure & $7(14.6)$ & $2(11)$ & $5(15)$ & $2(9.5)$ & 5 (18.5) \\
\hline \multicolumn{6}{|l|}{ Laboratory variables } \\
\hline $\begin{array}{l}\text { D-dimer - ng/mL, } \\
\text { median (IQR) }\end{array}$ & $\begin{array}{l}2304 \\
(1120- \\
5528)\end{array}$ & $\begin{array}{l}2018 \\
(1120- \\
6027)\end{array}$ & $\begin{array}{l}2512 \\
(1007- \\
18631)\end{array}$ & $\begin{array}{l}2038 \\
(1166- \\
4792)\end{array}$ & $\begin{array}{l}2449 \\
(1007- \\
18631)\end{array}$ \\
\hline $\begin{array}{l}\text { Serum creatinine - } \\
\mathrm{mg} / \mathrm{dL} \text {, median (IQR) }\end{array}$ & $\begin{array}{l}1.25 \\
(0.66-2.7)\end{array}$ & $\begin{array}{l}1.23 \\
(0.66-2.5)\end{array}$ & $\begin{array}{l}1.41(0.66- \\
4.59)\end{array}$ & $\begin{array}{l}0.98 \\
(0.62-1.8)\end{array}$ & $\begin{array}{l}1.45(0.69- \\
4.59)\end{array}$ \\
\hline Platelets count $-\times 10^{9} / \mathrm{L}$ & $\begin{array}{l}240(150- \\
333)\end{array}$ & $\begin{array}{l}293(146- \\
375)\end{array}$ & $\begin{array}{l}217(146- \\
310)\end{array}$ & $\begin{array}{l}257(170- \\
375)\end{array}$ & $\begin{array}{l}226(146- \\
310)\end{array}$ \\
\hline \multicolumn{6}{|l|}{ Intravenous sedation } \\
\hline Midazolam - no. (\%) & $44(88)$ & $12(66)$ & $23(71)$ & $18(85.7)$ & $26(89.7)$ \\
\hline Propofol - no. (\%) & $13(26)$ & $6(30)$ & $7(21)$ & $7(33.3)$ & $6(20.7)$ \\
\hline Ketamine - no. (\%) & $2(4)$ & 0 & $2(6)$ & $0(0)$ & $2(6.9)$ \\
\hline \multicolumn{6}{|l|}{$\begin{array}{l}\text { On the day of the first } \\
\text { assessment }\end{array}$} \\
\hline $\begin{array}{l}\text { Mean arterial pressure - } \\
\mathrm{mmHg}\end{array}$ & 79 (72-87) & $83(75-90)$ & $77(72-83)$ & $84(75-90)$ & $78(72-82)$ \\
\hline
\end{tabular}




\begin{tabular}{|c|c|c|c|c|c|}
\hline Characteristic & $\begin{array}{l}\text { Total } \\
(\mathrm{N}=50)\end{array}$ & $\begin{array}{l}\text { FO } \\
(N=15)\end{array}$ & $\begin{array}{l}\text { UO } \\
(\mathrm{N}=35)\end{array}$ & $\begin{array}{l}\text { Survivors } \\
(\mathrm{N}=20)\end{array}$ & $\begin{array}{l}\text { Non- } \\
\text { survivors } \\
(\mathrm{N}=30)\end{array}$ \\
\hline $\begin{array}{l}\text { Mean arterial pressure < } \\
\mathrm{mmHg}-\mathrm{no} .(\%)\end{array}$ & $2(4)$ & 0 & $2(6)$ & $0(0)$ & $2(6.9)$ \\
\hline $\begin{array}{l}\text { Vasopressor use - no. } \\
(\%)\end{array}$ & $25(50.0)$ & $9(50)$ & $16(32)$ & $8(38.1)$ & $17(77.3)$ \\
\hline Heart rate $-\mathrm{mmHg}$ & $87(75-98)$ & $75(72-81)$ & $\begin{array}{l}87(79- \\
104)\end{array}$ & $78(72-93)$ & $\begin{array}{l}89(82- \\
104)\end{array}$ \\
\hline Respiratory rate - rpm & $26(22-30)$ & $25(22-31)$ & $29(23-32)$ & $26(22-29)$ & $28(22-32)$ \\
\hline $\begin{array}{l}\text { Oxygen saturation }\left(\mathrm{SaO}_{2}\right) \\
-\%\end{array}$ & $93(90-95)$ & $94(90-97)$ & $92(90-95)$ & $93(91-94)$ & $92(90-95)$ \\
\hline Hypoxemia - no. (\%) & $3(6)$ & $1(5)$ & $2(6)$ & $1(4.8)$ & $2(6.9)$ \\
\hline $\mathrm{PaCO}_{2}-\mathrm{mmHg}$ & $\begin{array}{l}40.7 \\
(37.4- \\
48.8)\end{array}$ & $39(36-44)$ & $42(40-44)$ & $\begin{array}{l}39.9(37- \\
44)\end{array}$ & $\begin{array}{l}42.3(38- \\
44)\end{array}$ \\
\hline Hypercapnia - no. (\%) & $16(32)$ & $4(22)$ & $12(37)$ & $5(23.8)$ & $11(37.9)$ \\
\hline Temperature $-{ }^{\circ} \mathrm{C}$ & $\begin{array}{l}36.1 \\
(35.6- \\
36.9)\end{array}$ & $\begin{array}{l}36(35.8- \\
37)\end{array}$ & $\begin{array}{l}36.5(35.5- \\
38)\end{array}$ & $\begin{array}{l}36.2(35- \\
37)\end{array}$ & $\begin{array}{l}36.2(35- \\
38)\end{array}$ \\
\hline Hemoglobin - g/dL & $\begin{array}{l}11.1(8.8- \\
12.7)\end{array}$ & $\begin{array}{l}11.2(9.9- \\
12.9)\end{array}$ & $\begin{array}{l}10.3(8.7- \\
13.1)\end{array}$ & $\begin{array}{l}11.6 \\
(10.4- \\
12.4)\end{array}$ & $\begin{array}{l}10.2(8.7- \\
13.1)\end{array}$ \\
\hline $\begin{array}{l}\mathrm{PaO}_{2} / \mathrm{FiO}_{2} \text {-median } \\
(\mathrm{IQR})\end{array}$ & $\begin{array}{l}145(127- \\
182)\end{array}$ & $\begin{array}{l}178(141- \\
216)\end{array}$ & $\begin{array}{l}132(98- \\
151)\end{array}$ & $\begin{array}{l}167(138- \\
216)\end{array}$ & $\begin{array}{l}136(98- \\
151) *\end{array}$ \\
\hline $\begin{array}{l}\text { Renal replacement } \\
\text { therapy - no. (\%) }\end{array}$ & $13(31.7)$ & $5(27)$ & $8(25)$ & $5(26.3)$ & $8(36.4)$ \\
\hline
\end{tabular}

\section{ICC and CVH assessment}

On the first assessment $(\mathrm{N}=50)$, mCBFV was $63(32-140) \mathrm{cm} / \mathrm{sec}$, PI was $1.04(0.65-2.2)$, elCP 16 (148) $\mathrm{mmHg}$ and eCPP 63 (30-90) mmHg. Twenty-six (52\%) patients had abnormal mCBFV; low mCBFV $(<40 \mathrm{~cm} / \mathrm{s})$ were observed in 5 patients, and elevated mCBFV were observed in 21 patients. Nineteen (38\%) patients with elevated $\mathrm{PI}, 14(28 \%)$ had high elCP and 11 (22\%) had abnormal eCPP (4 with low eCPP and 7 with high eCPP). Thirty-three (66\%) patients had abnormal P2/P1 ratio (16 within 1.01-1.2 and $17>1.2$ - Fig. 2). The CVH/ICC score was 8.5 (7-11.75).

On the second assessment $(\mathrm{N}=29)$, mCBFV was $68(30-173) \mathrm{cm} / \mathrm{sec}$, PI was $0.99(0.5-1.8)$, elCP 15 (331) $\mathrm{mmHg}$ and eCPP 71 (41-97) $\mathrm{mmHg}$. Twelve (41\%) patients had abnormal mCBFV; low mCBFV (< $40 \mathrm{~cm} / \mathrm{s}$ ) were observed in two patients, and elevated mCBFV $(>70 \mathrm{~cm} / \mathrm{s})$ were observed in ten patients. 
10 (34\%) patients with elevated PI, 7 (24\%) patients with high elCP, 14 (48\%) patients with abnormal eCPP (2 low and 12 high), 15 (51\%) patients with abnormal P2/P1 ratio, (4 for 1.01-1.2 and 11 for >1.2).

For these 29 patients, P2/P1 (1.05 [0.96-1.27] vs. 1.08 [0.87-1.28]; $p=0.86), \operatorname{mCBFV~(73~[53-82]~vs.~} 60$ $[51-80] \mathrm{cm} / \mathrm{sec} ; \mathrm{p}=0.27), \mathrm{PI}(0.95$ [0.85-1.27] vs. 0.92 [0.86-1.21]; $p=0.58)$, elCP (13 [9-21] vs. 14 [10$20] \mathrm{mmHg} ; \mathrm{p}=0.96)$ and eCPP $(68[60-75]$ vs. $75[60-85] \mathrm{mmHg} ; \mathrm{p}=0.09)$ were similar between the two assessments. Table 3 shows the concordance between abnormal values for the different parameters measured on first assessment; most of patients abnormal eICP also had abnormal PI aor P2/P1 values.

Table 3

Concordance of abnormal values for each technique on the first assessment $(n=50)$.

\begin{tabular}{|c|c|c|c|c|c|}
\hline & $\begin{array}{l}\text { Abnormal } \\
\text { mCBFv } \\
n=26\end{array}$ & $\begin{array}{l}\text { Abnormal } \\
\text { PI } \\
n=19\end{array}$ & $\begin{array}{l}\text { Abnormal } \\
\text { elCP } \\
n=14\end{array}$ & $\begin{array}{l}\text { Abnormal } \\
\text { eCPP } \\
n=11\end{array}$ & $\begin{array}{l}\text { Abnorma } \\
\text { P2/P1 } \\
\mathrm{n}=33\end{array}$ \\
\hline $\begin{array}{l}\text { Abnormal } \\
\text { mCBFV } \\
n=26\end{array}$ & - & $11(42)$ & $10(38)$ & $7(27)$ & $18(69)$ \\
\hline $\begin{array}{l}\text { Abnormal PI } \\
n=19\end{array}$ & $11(58)$ & - & $13(68)$ & $5(26)$ & $14(73)$ \\
\hline $\begin{array}{l}\text { Abnormal elCP } \\
n=14\end{array}$ & $10(71)$ & $13(93)$ & - & $6(42)$ & $13(93)$ \\
\hline $\begin{array}{l}\text { Abnormal eCPP } \\
n=11\end{array}$ & $7(63)$ & $5(45)$ & $6(54)$ & - & $6(54)$ \\
\hline $\begin{array}{l}\text { Abnormal } \\
\text { P2/P1 } \\
n=33\end{array}$ & $18(54)$ & $14(42)$ & $13(39)$ & $6(18)$ & - \\
\hline
\end{tabular}

The CVH/ICC score was 8 (6-10) on the second assessment; for the 29 patients with two assessments, the $\mathrm{CVH} / \mathrm{ICC}$ score was similar at the two time-points $(\mathrm{p}=0.48)$.

\section{$\mathrm{CVH} / \mathrm{ICCl}$ and primary outcome}

On the first assessment $(\mathrm{N}=50), \mathrm{mCBFV}(66$ [43-80] vs. 63 [53-73] cm/sec; $\mathrm{p}=0.70), \mathrm{PI}(1.01[0.90-$ 1.40] vs. 0.95 [0.85-1.10]; $p=0.13)$ and $\operatorname{eCPP}(64$ [56-71] vs. 64 [60-74] $\mathrm{mmHg} ; \mathrm{p}=0.35)$ values were similar between patients with UO and favorable outcome. However, P2/P1 (1.20 [1.00-1.28] vs. 1.00 $[0.88-1.16] ; p=0.03)$ and elCP $(14$ [11-25] vs. 11 [7-15] mmHg; $p=0.01)$ were significantly higher among patients with $\mathrm{UO}$ than others. 
Also, the proportion of patients with abnormal mCBFV (21/35, $60 \%$ vs. $5 / 15,33 \%$, OR 3.00 [0.90-9.97]; p $=0.08), \mathrm{PI}(16 / 35,46 \%$ vs. $3 / 15,20 \%$, OR 3.36 [0.89-12.45]; $p=0.09)$, elCP $(12 / 35,34 \%$ vs. $2 / 15,13 \%$, OR 3.39 [0.71-16.75]; $p=0.13)$, eCPP (9/35, 26\% vs. $2 / 15,13 \%$, OR 2.29 [0.42-11.43]; $p=0.33$ ) and P2/P1 values $(26 / 35,74 \%$ vs. $7 / 15,47 \%$, OR 3.30 [0.95-11.36]; $p=0.06)$ were similar between groups.

Patients with UO had a significantly higher CVH/ICC score (9 [8-12] vs. 6 [5-7]; $p<0.001)$ than those with favorable outcome (Fig. 3). The AUROC for CVH/ICC score to predict UO was 0.86 (95\% Cls $0.75-0.97$ ); a score $>8.5$ had $63(46-77) \%$ sensitivity and $87(62-97) \%$ specificity to predict UO. One out of $5(20 \%)$ patients with no $\mathrm{CVH} / \mathrm{ICC}$ impairment had UO; 7/15 (46\%) patients with mild CVH/ICC impairment had UO; 10/12 (83\%) patients with moderate CVH/ICC impairment had UO; 17/18 (94\%) patients with severe $\mathrm{CVH} / \mathrm{ICC}$ impairment had UO $(\mathrm{p}=0.001)$.

\section{$\mathrm{CVH} / \mathrm{ICCl}$ and ICU mortality}

On the first assessment $(\mathrm{N}=50), \operatorname{mCBFV}(60[42-80]$ vs. $72[54-80] \mathrm{cm} / \mathrm{sec} ; \mathrm{p}=0.16), \mathrm{PI}(1.00[0.92-$ 1.37 ] vs. 0.96 [0.86-1.29]; $p=0.26)$, elCP (14 [9-23] vs. 13 [8-17] $\mathrm{mmHg} ; \mathrm{p}=0.48)$, eCPP (64 [54-70] vs. 66 [60-75] mmHg; $p=0.12$ ) and P2/P1 values (1.14 [0.93-1.25] vs. 1.08 [0.96-1.27]; $p=0.84)$ were similar between non-survivors and survivors. Also, the proportion of patients with abnormal mCBFV, $\mathrm{PI}$, elCP, eCPP and P2/P1 values were similar between groups, as the CVH/ICC score (9 [7-12] vs. 7 [6-11]; $\mathrm{P}$ $=0.13)$.

\section{Discussion}

In this single center prospective study, we observed that brain hemodynamics were impaired in a large proportion of critically ill COVID-19 patients on mechanical ventilation. In particular, early assessment of these patients showed higher intracranial pressure and lower brain compliance among those who were still on ventilation or who had died within the first 7 days since study admission. Moreover, a score composed on different parameters related to brain perfusion and compliance could identify such patients with a high accuracy. Nevertheless, these alterations were not associated with ICU mortality.

Currently, there are no data on alterations in intracranial hemodynamics and/or compliance in COVID-19 patients, although several studies have shown an increased occurrence of cerebrovascular events in lowrisk patients, being associated with coagulation disorders and the formation of clots in the large intracranial vessels or into the brain microvasculature. ${ }^{32}$ Nervous system invasion mechanism has been described as direct viral penetration of nerve endings and traveling within the axons or by the systemic circulation, via the infected endothelial cells of brain vessels or epithelial cells in the choroid plexus or the disruption of the blood-brain barrier; also, neuroinflammation, which is triggered by systemic inflammatory response and organ damage, can contribute to brain dysfunction through activation of microglial cells. ${ }^{33}$ The clinical consequences of this phenomena are consistent with cerebrovascular events, brain swelling, seizures and encephalopathy, which could be further enhanced by the use of 
specific therapies, such as mechanical ventilation, sedatives or extra-corporeal membrane oxygenation (ECMO). ${ }^{34}$

The role of TCD-derived parameters (mCBFV, PI, elCP and eCPP) on the assessment of cerebral hemodynamics in critically ill patients without a primary brain injury is well established, with relevant data on the role of altered autoregulation in the pathogenesis of septic encephalopathy ${ }^{35}$ or of reduced mCBFV in association with severe post-anoxic brain damage, ${ }^{36}$ although the association with long-term neurological outcome needs to be further evaluated. In hospitalized COVID-19 patients, higher mCBV and lower vasoreactivity were observed than matched healthy volunteers ${ }^{37}$. Also, in a small recent study using cerebral ultrasound, elCP was higher and diastolic CBFV lower in COVID-19 patients developing neurological complications when compared to others ${ }^{38}$. The authors added also the estimation of ICP using the optic nerve sheath diameter measure (ONSD) measurement with cerebral ultrasound, which was not available in our study. Moreover, mortality was higher in our study than this report (60\% vs.33\%), and differences in patients' selection and management as well as a different study endpoint precluded any additional comparison. Moreover, there is lack of studies dealing with this B4C device in critically ill patients; although this new technique provides an unique assessment of cerebral compliance, which would be complementary to TCD-derived variables, more prospective data are needed to validate this noninvasive and relatively low-cost technique as a reliable bedside neuromonitoring in critically ill patients.

We did not specifically evaluate which factors could influence alterations in brain hemodynamics or compliance. Changes in $\mathrm{PaCO}_{2}$, mean arterial pressure, $\mathrm{pH}$, sodium or temperature could also lead to altered brain hemodynamics. ${ }^{39-41}$ Because of the relatively small sample size and different patterns of TCD and P2/P1 alterations, we could not assess the association of systemic abnormalities with some specific patterns, such as low mCBFV, high elCP or P2/P1. However, as all these variables are complementary and evaluate different aspect of brain hemodynamics, we could obtain a composite derived score with a high predictive accuracy for early UO. Further studies would be required to confirm the validity of such score and its association with clinically relevant neurologic symptoms or syndromes (i.e. encephalopathy, delirium, ischemic events) or its correlation with other neuromonitoring tools, such as brain oximetry or electroencephalography.

This study has several limitations to acknowledge. First, our findings showed association and not causality between UO and alterations in cerebral hemodynamics. Routine daily assessment of these variables as of potential therapies to restore "normal" brain hemodynamics will be in this setting. Second, the correlation between the B4C system and other surrogate of brain compliance, such as invasive ICP monitoring, is not validated yet. The thresholds applied in our study were however extrapolated from the previous knowledge on ICC and ICP research. As this system acquires intracranial information through an extracranial technique, precaution is needed. Third, we could not perform neurological imaging during the study period, which is a hindrance to elucidate the etiology of the alterations in intracranial pressure pulse waveform in COVID-19, whether as primary CNS injury or secondary to respiratory or other systemic complications. Forth, availability of operators to assess brain hemodynamics restricted study exclusively 
for severe COVID-19 admitted to the ICU. Finally, we used a composite endpoint of early systemic dysfunction, which is not specific for brain damage; long-term neurological assessment should be evaluated in future studies in association with early disturbances of brain perfusion and compliance.

\section{Conclusions}

In this study, early alteration of brain hemodynamics and compliance were associated with the severity of COVID-19 on day 7, including death or dependency from mechanical ventilation. These findings claim for larger investigations on the role of neuromonitoring seem in this setting to further understand the role of such disturbances on clinically relevant patients' outcome.

\section{Declarations}

\section{Authors' contributions}

SB conceived, executed the study and designed the paper. FST and FA performed statistical analysis and comprehensive paper review. All authors participated in drafting, acquisition of data and reviewing. All authors read and approved the final version of the manuscript.

\section{Competing interests and consent}

The authors declare no competing interest for this study and give consent for its publication.

\section{Consent for publication}

The authors revised this final version and give consent for its publication.

\section{Funding}

None.

\section{Availability of data and material}

Datasets used and/or analyzed during the current study are available from the corresponding author on reasonable request.

\section{Ethics approval}

The protocol was approved by the Research Ethical Committee at Sao Paulo University Medical School. The care and handling of the animals were in accord with the National Institutes of Health guidelines.

\section{Acknowledgements}

We thank Gustavo Frigieri for support with the Brain4care system. 


\section{References}

1. Li YC, Bai WZ, Hashikawa T. The neuroinvasive potential of SARS-CoV2 may play a role in the respiratory failure of COVID-19 patients. J Med Virol. 2020.

2. Baig AM, Khaleeq A, Ali U, Syeda H. Evidence of the COVID-19 Virus Targeting the CNS: Tissue Distribution, Host-Virus Interaction, and Proposed Neurotropic Mechanisms. ACS Chem Neurosci. 2020;11(7):995-8.

3. Needham EJ, Chou SH, Coles AJ, Menon DK. Neurological Implications of COVID-19 Infections. Neurocrit Care. 2020;32(3):667-71.

4. Bridwell R, Long B, Gottlieb M. Neurologic complications of COVID-19. Am J Emerg Med. 2020.

5. Niazkar HR, Zibaee B, Nasimi A, Bahri N. The neurological manifestations of COVID-19: a review article. Neurol Sci. 2020.

6. Solomon IH, Normandin E, Bhattacharyya S, et al. Neuropathological Features of Covid-19. N Engl J Med. 2020.

7. Toscano G, Palmerini F, Ravaglia S, et al. Guillain-Barre Syndrome Associated with SARS-CoV-2. N Engl J Med. 2020.

8. Gutierrez-Ortiz C, Mendez A, Rodrigo-Rey S, et al. Miller Fisher Syndrome and polyneuritis cranialis in COVID-19. Neurology. 2020.

9. Moreau A, Ego A, Vandergheynst F, et al. Cytotoxic lesions of the corpus callosum (CLOCCs) associated with SARS-CoV-2 infection. J Neurol. 2020.

10. Spallazzi M, Morelli N, Taga A. COVID-19 and neurologic manifestations: a still missing link and a call for neurologists. Neurol Sci. 2020.

11. Wu Y, Xu X, Chen Z, et al. Nervous system involvement after infection with COVID-19 and other coronaviruses. Brain Behav Immun. 2020.

12. Delanghe JR, Speeckaert MM, De Buyzere ML. The host's angiotensin-converting enzyme polymorphism may explain epidemiological findings in COVID-19 infections. Clin Chim Acta. 2020;505:192-3.

13. Paterson RW, Brown RL, Benjamin L, et al. The emerging spectrum of COVID-19 neurology: clinical, radiological and laboratory findings. Brain. 2020.

14. Rogers JP, Chesney E, Oliver D, et al. Psychiatric and neuropsychiatric presentations associated with severe coronavirus infections: a systematic review and meta-analysis with comparison to the COVID19 pandemic. Lancet Psychiatry. 2020;7(7):611-27.

15. Kochanek PM, Tasker RC, Carney N, et al. Guidelines for the Management of Pediatric Severe Traumatic Brain Injury, Third Edition: Update of the Brain Trauma Foundation Guidelines. Pediatr Crit Care Med. 2019;20(3S Suppl 1):1-82.

16. Frigieri G, Andrade RAP, Dias C, et al. Analysis of a Non-invasive Intracranial Pressure Monitoring Method in Patients with Traumatic Brain Injury. Acta Neurochir Suppl. 2018;126:107-10. 
17. Vilela GH, Cabella B, Mascarenhas S, et al. Validation of a New Minimally Invasive Intracranial Pressure Monitoring Method by Direct Comparison with an Invasive Technique. Acta Neurochir Suppl. 2016;122:97-100.

18. Cabella B, Vilela GH, Mascarenhas S, et al. Validation of a New Noninvasive Intracranial Pressure Monitoring Method by Direct Comparison with an Invasive Technique. Acta Neurochir Suppl. 2016;122:93-6.

19. Brasil S, Bor-Seng-Shu E, de-Lima-Oliveira M, et al. Computed tomography angiography accuracy in brain death diagnosis. J Neurosurg. 2019:1-9.

20. Ballestero MFM, Frigieri G, Cabella BCT, de Oliveira SM, de Oliveira RS. Prediction of intracranial hypertension through noninvasive intracranial pressure waveform analysis in pediatric hydrocephalus. Childs Nerv Syst. 2017;33(9):1517-24.

21. Nucci CG, De Bonis $P$, Mangiola A, et al. Intracranial pressure wave morphological classification: automated analysis and clinical validation. Acta Neurochir (Wien). 2016;158(3):581-8. discussion 588.

22. Nag DS, Sahu S, Swain A, Kant S. Intracranial pressure monitoring: Gold standard and recent innovations. World J Clin Cases. 2019;7(13):1535-53.

23. Panerai RB, Hudson V, Fan L, et al. Assessment of dynamic cerebral autoregulation based on spontaneous fluctuations in arterial blood pressure and intracranial pressure. Physiol Meas. 2002;23(1):59-72.

24. Robba C, Pozzebon S, Moro B, Vincent JL, Creteur J, Taccone FS. Multimodal non-invasive assessment of intracranial hypertension: an observational study. Crit Care. 2020;24(1):379.

25. Czosnyka M, Matta BF, Smielewski P, Kirkpatrick PJ, Pickard JD. Cerebral perfusion pressure in headinjured patients: a noninvasive assessment using transcranial Doppler ultrasonography. $\mathrm{J}$ Neurosurg. 1998;88(5):802-8.

26. Rasulo FA, Bertuetti R, Robba C, et al. The accuracy of transcranial Doppler in excluding intracranial hypertension following acute brain injury: a multicenter prospective pilot study. Crit Care. 2017;21(1):44.

27. Morales DR, Conover MM, You SC, et al. Renin-angiotensin system blockers and susceptibility to COVID-19: a multinational open science cohort study. medRxiv. 2020.

28. Fisman DN, Greer AL, Tuite AR. Age Is Just a Number: A Critically Important Number for COVID-19 Case Fatality. Ann Intern Med. 2020.

29. Wu J, Huang J, Zhu G, et al. Elevation of blood glucose level predicts worse outcomes in hospitalized patients with COVID-19: a retrospective cohort study. BMJ Open Diabetes Res Care. 2020;8(1).

30. Wong SH, Lui RN, Sung JJ. Covid-19 and the digestive system. J Gastroenterol Hepatol. 2020;35(5):744-8.

31. Kieser M, Wassmer G. On the Use of the Upper Confidence Limit for the Variance from a Pilot Sample for Sample Size Determination. Biometrical Journal. 1996;38(8):941-9. 
32. Li Y, Li M, Wang M, et al. Acute cerebrovascular disease following COVID-19: a single center, retrospective, observational study. Stroke Vasc Neurol. 2020;5(3):279-84.

33. Fotuhi M, Mian A, Meysami S, Raji CA. Neurobiology of COVID-19. J Alzheimers Dis. 2020;76(1):319.

34. Battaglini D, Brunetti I, Anania P, et al. Neurological Manifestations of Severe SARS-CoV-2 Infection: Potential Mechanisms and Implications of Individualized Mechanical Ventilation Settings. Front Neurol. 2020;11:845.

35. Crippa IA, Subira C, Vincent JL, et al. Impaired cerebral autoregulation is associated with brain dysfunction in patients with sepsis. Crit Care. 2018;22(1):327.

36. Taccone FS, Crippa IA, Creteur J, Rasulo F. Estimated cerebral perfusion pressure among post-cardiac arrest survivors. Intensive Care Med. 2018;44(6):966-7.

37. Sonkaya AR, OztUrk B, Karada SO. Cerebral hemodynamic alterations in patients with Covid-19. Turk J Med Sci. 2020.

38. Battaglini D, Santori G, Chandraptham K, et al. Neurological Complications and Noninvasive Multimodal Neuromonitoring in Critically III Mechanically Ventilated COVID-19 Patients. Frontiers in Neurology. 2020;11(1482).

39. van der Kleij LA, De Vis JB, de Bresser J, Hendrikse J, Siero JCW. Arterial CO2 pressure changes during hypercapnia are associated with changes in brain parenchymal volume. Eur Radiol Exp. 2020;4(1):17.

40. Prakash K, Chandran DS, Khadgawat R, Jaryal AK, Deepak KK. Correction for blood pressure improves correlation between cerebrovascular reactivity assessed by breath holding and $6 \% \mathrm{CO}(2)$ breathing. J Stroke Cerebrovasc Dis. 2014;23(4):630-5.

41. Meng L, Gelb AW. Regulation of cerebral autoregulation by carbon dioxide. Anesthesiology. 2015;122(1):196-205.

\section{Figures}




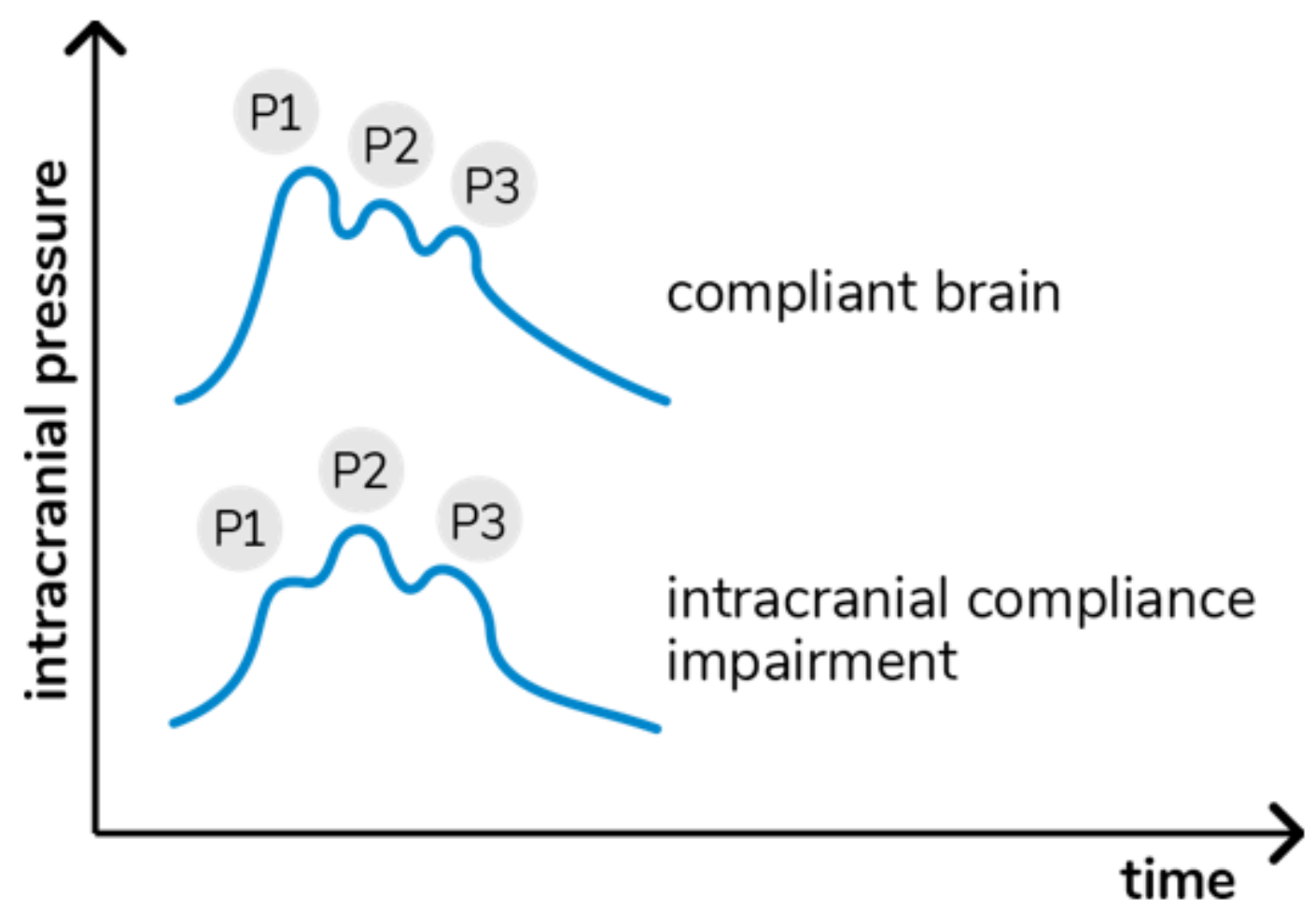

Figure 1

Intracranial pressure waves morphology in accordance with cerebral compliance.

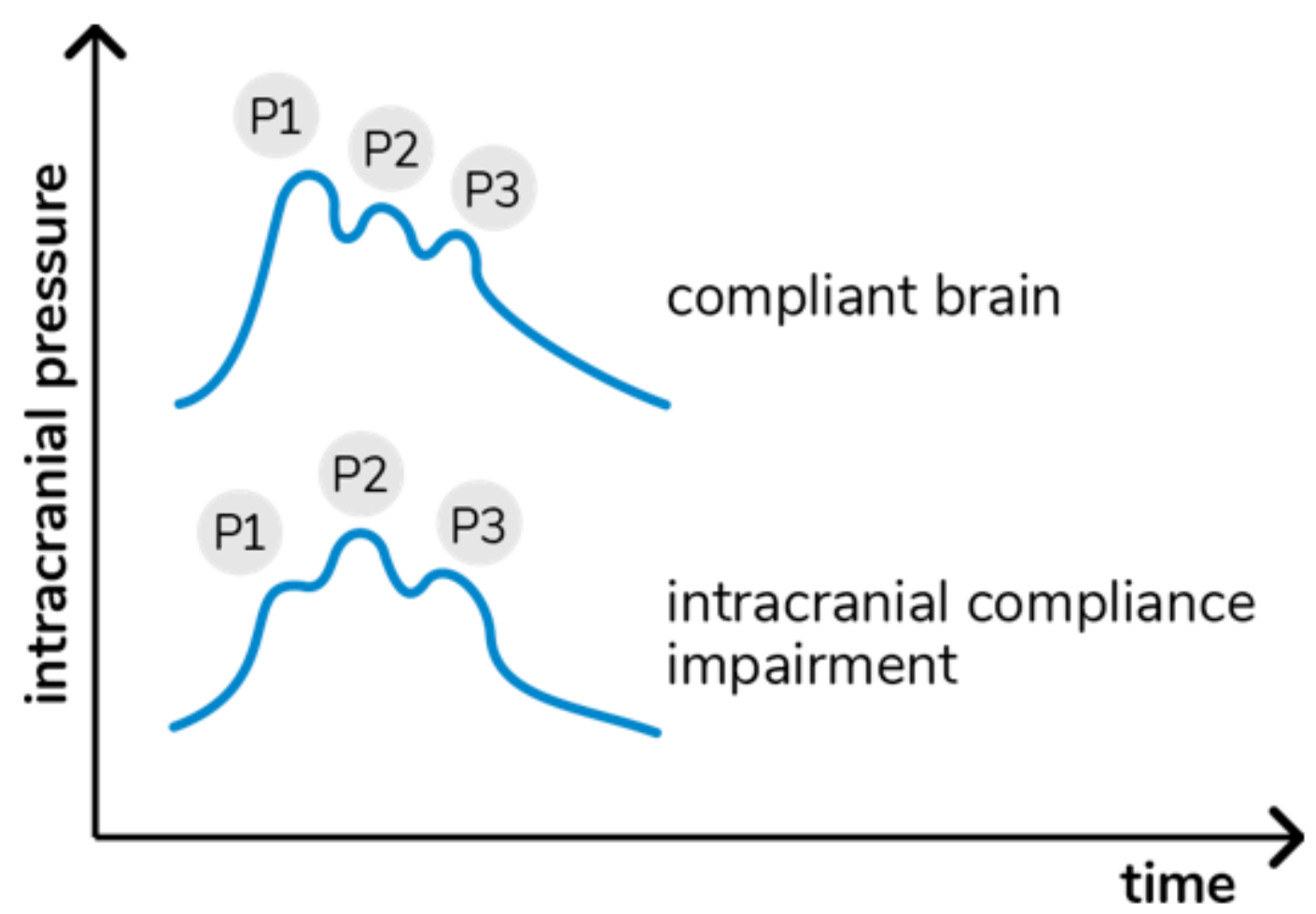

Figure 1 
Intracranial pressure waves morphology in accordance with cerebral compliance.

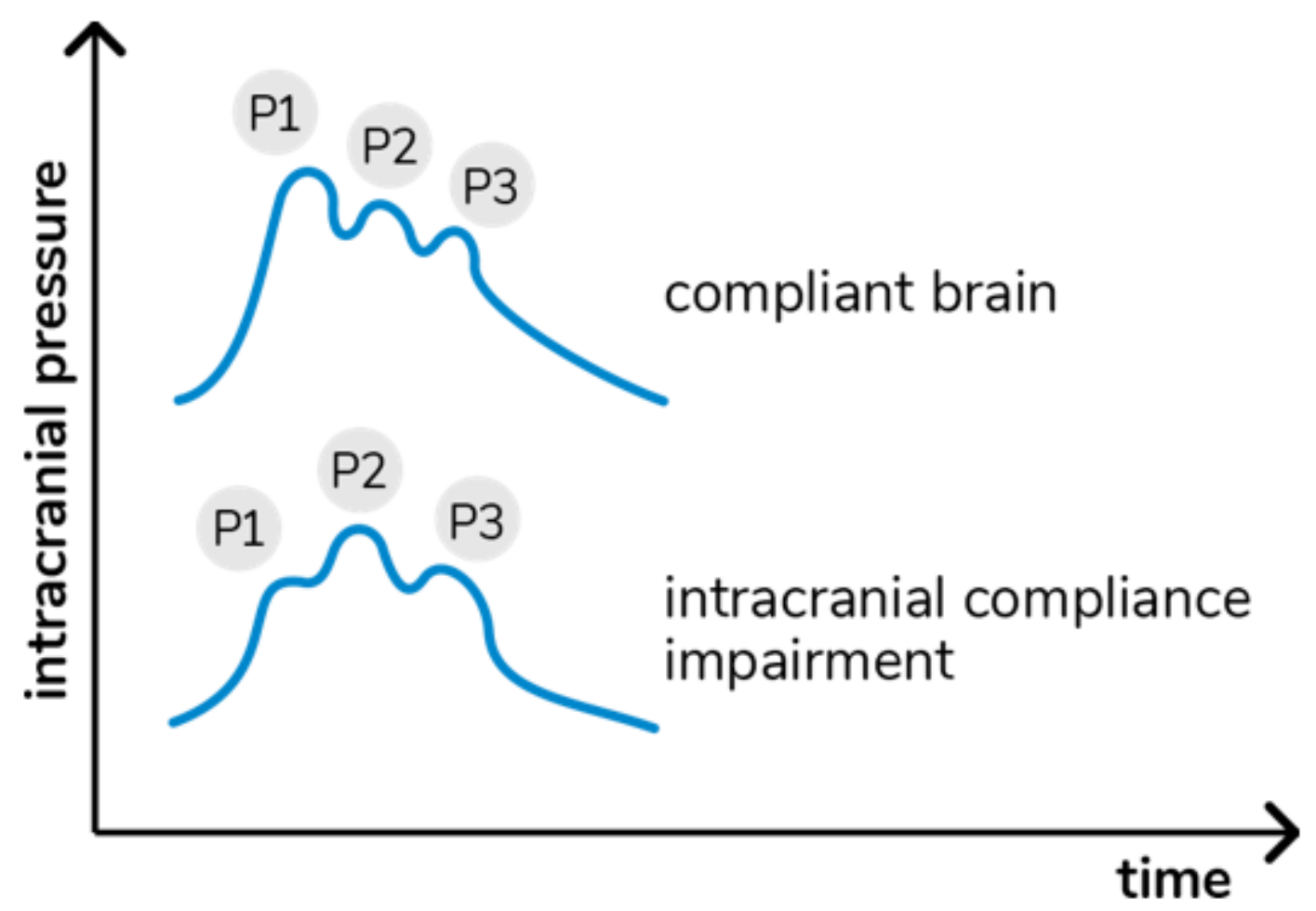

Figure 1

Intracranial pressure waves morphology in accordance with cerebral compliance. 


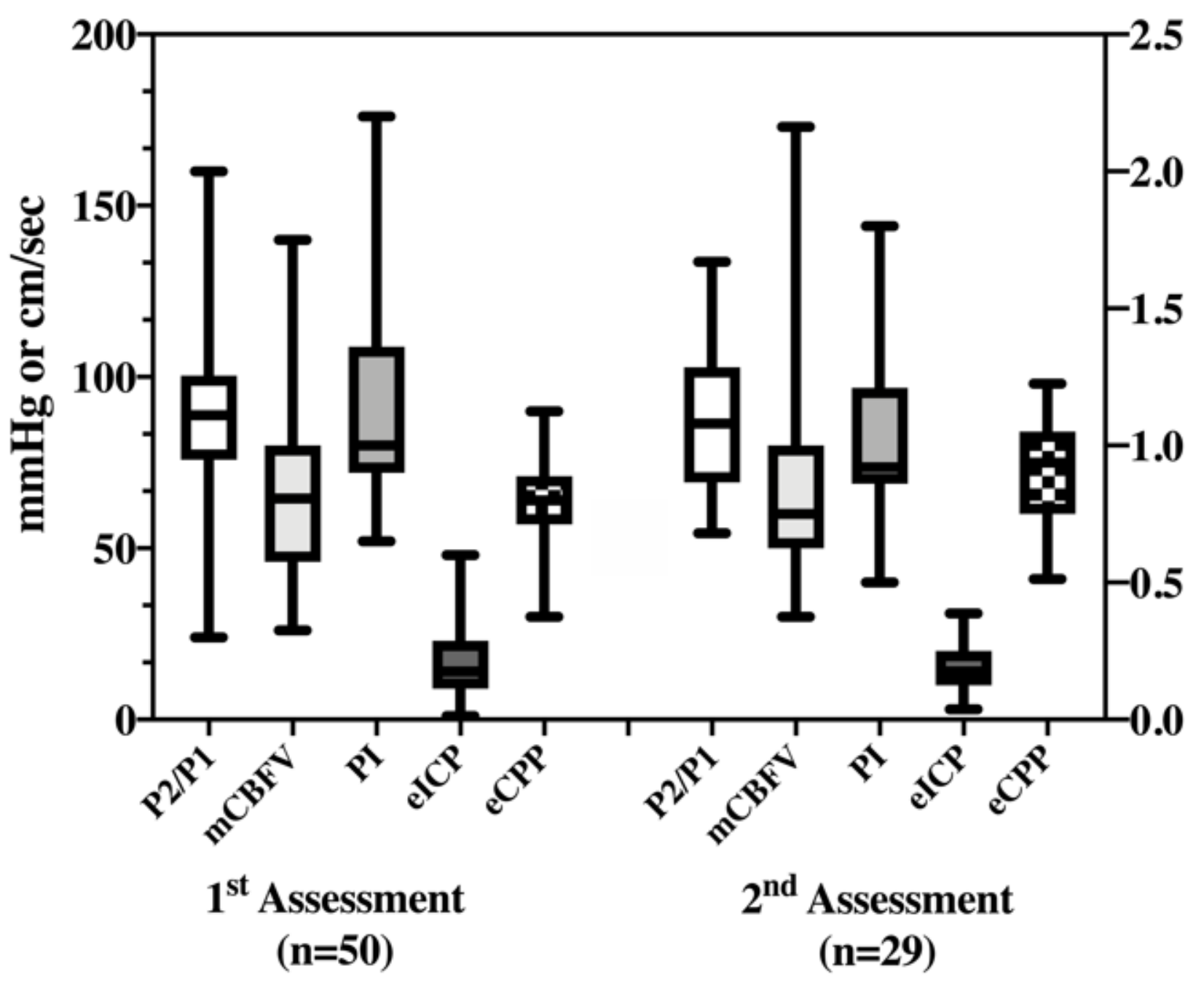

Figure 2

Median values of all variables derived from transcranial doppler and cerebral compliance (P2/P1) measurement, on the first and second assessment. mCBFV = mean cerebral blood flow velocity $(\mathrm{cm} / \mathrm{sec})$; $\mathrm{PI}=$ pulsatility index; elCP = estimated intracranial pressure $(\mathrm{mmHg}) ; \mathrm{eCPP}=$ estimated cerebral perfusion pressure $(\mathrm{mmHg})$. 


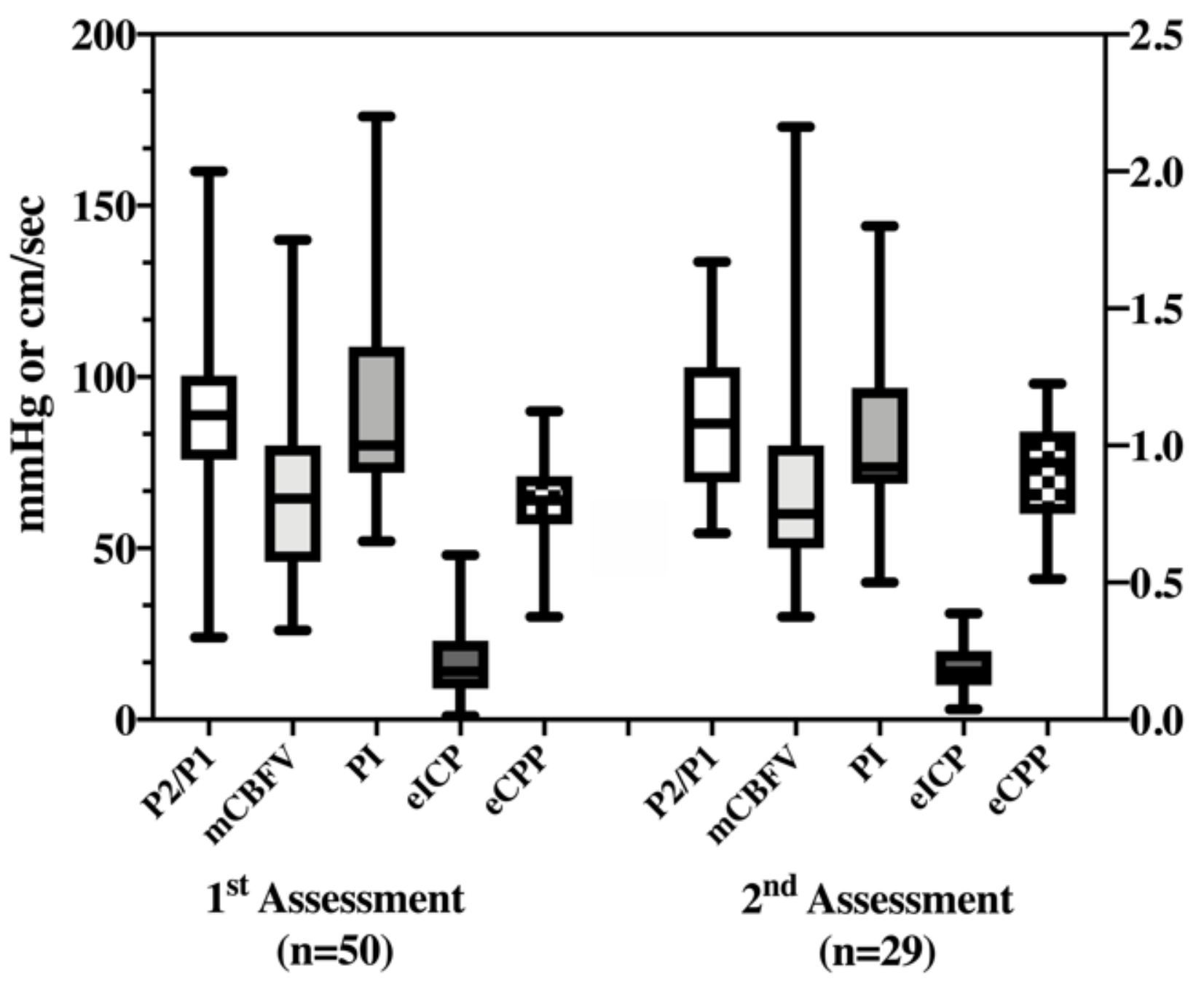

Figure 2

Median values of all variables derived from transcranial doppler and cerebral compliance (P2/P1) measurement, on the first and second assessment. mCBFV = mean cerebral blood flow velocity $(\mathrm{cm} / \mathrm{sec})$; $\mathrm{PI}=$ pulsatility index; elCP = estimated intracranial pressure $(\mathrm{mmHg}) ; \mathrm{eCPP}=$ estimated cerebral perfusion pressure $(\mathrm{mmHg})$. 


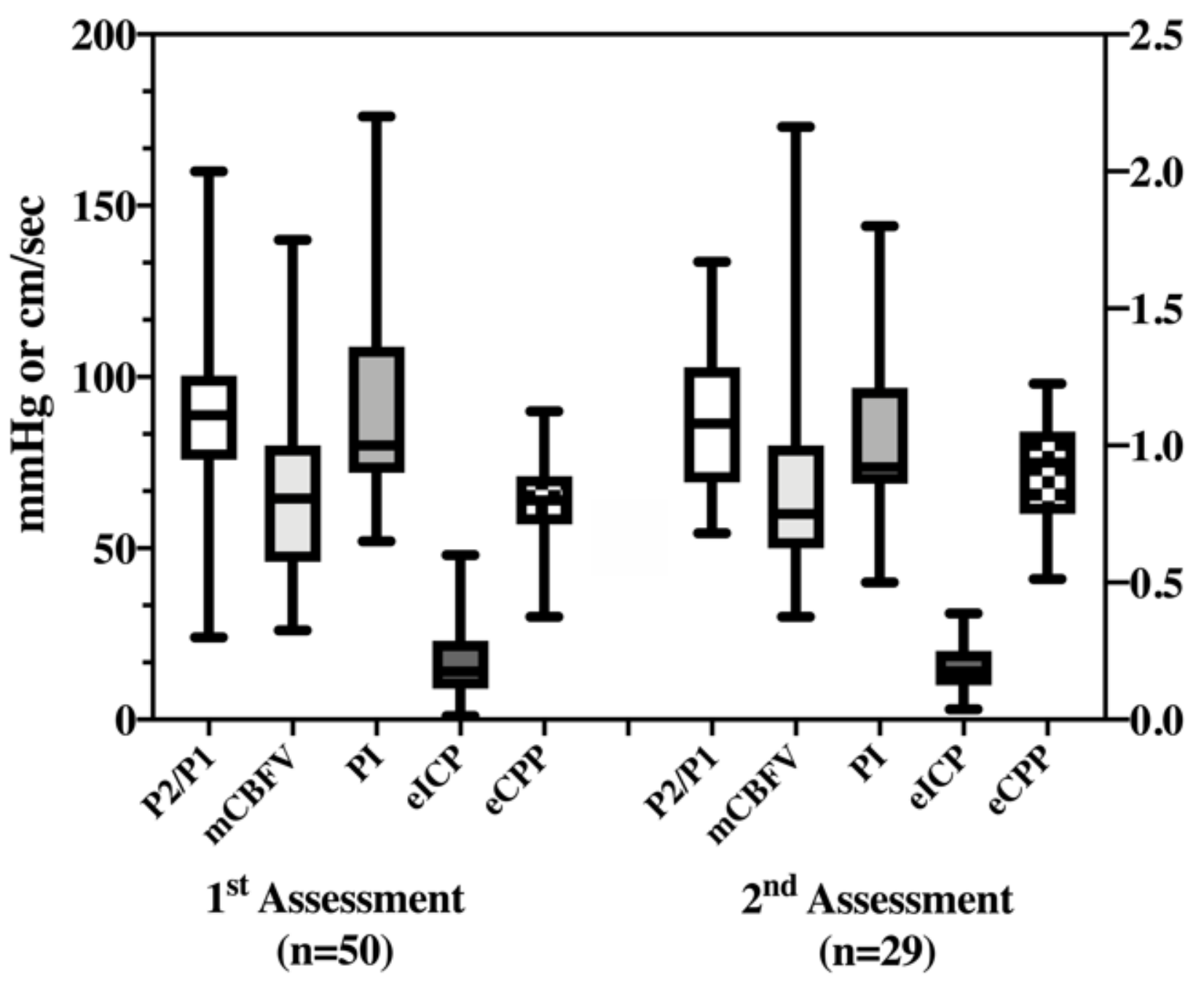

Figure 2

Median values of all variables derived from transcranial doppler and cerebral compliance (P2/P1) measurement, on the first and second assessment. mCBFV = mean cerebral blood flow velocity $(\mathrm{cm} / \mathrm{sec})$; $\mathrm{PI}=$ pulsatility index; elCP = estimated intracranial pressure $(\mathrm{mmHg}) ; \mathrm{eCPP}=$ estimated cerebral perfusion pressure $(\mathrm{mmHg})$. 

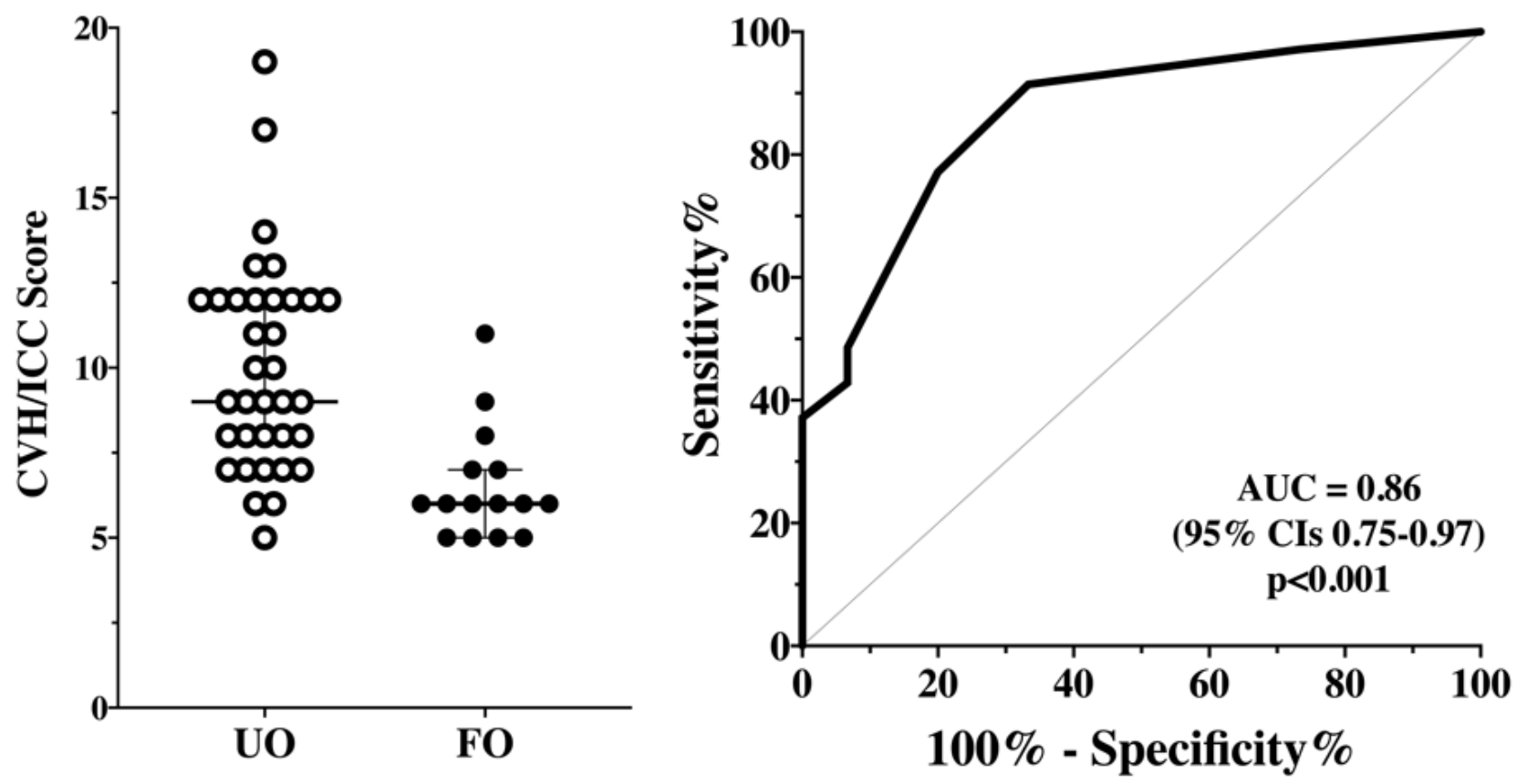

Figure 3

$\mathrm{CVH} / \mathrm{ICC}$ score between patient with unfavorable (UO) and favorable outcome (FO) on the first assessment ( $\mathrm{n}=50$ - Left Panel). The area under the receiver operating characteristic (ROC) for $\mathrm{CVH} / \mathrm{ICC}$ score to predict UO is shown on the Right Panel.
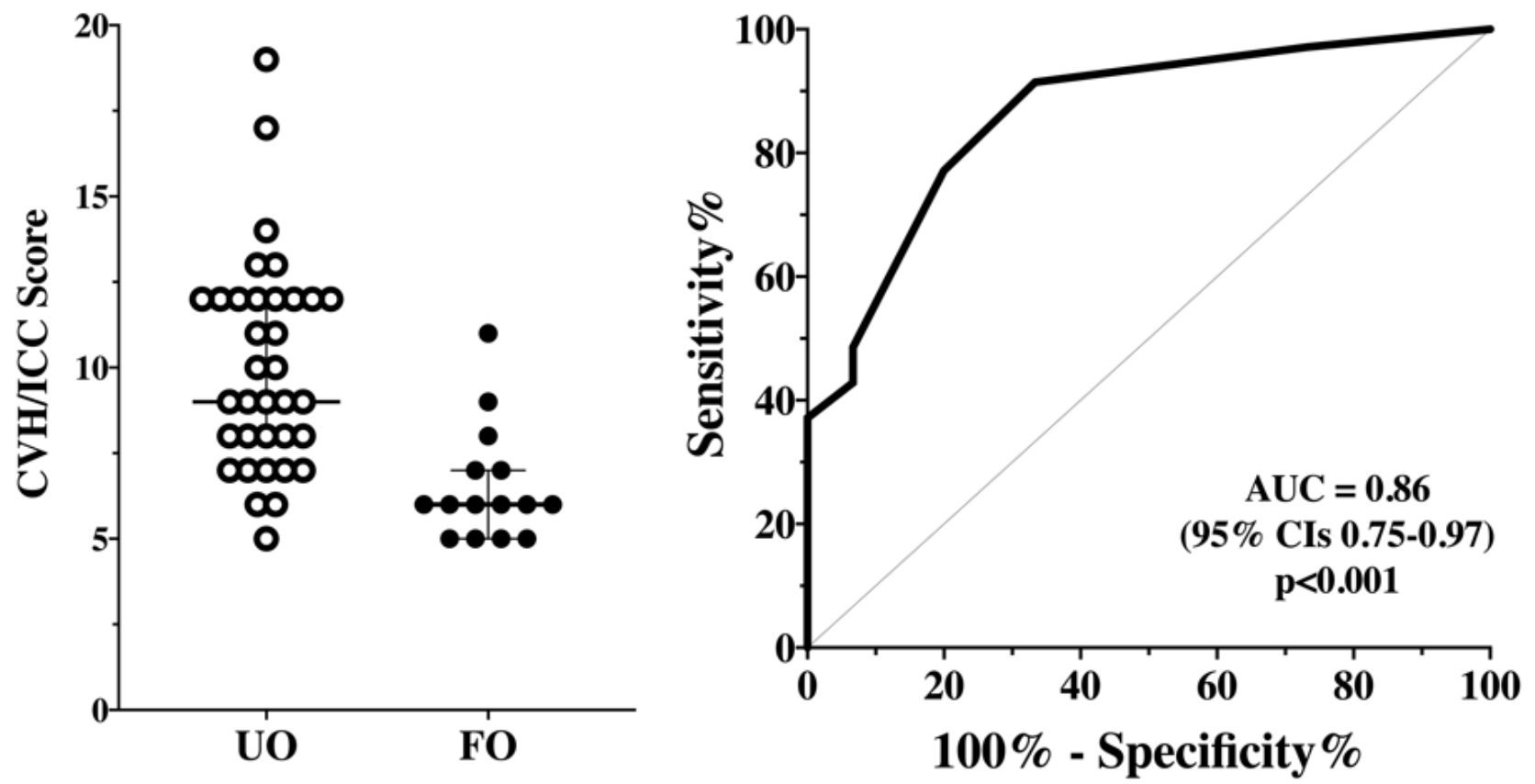

Figure 3

$\mathrm{CVH} / \mathrm{ICC}$ score between patient with unfavorable (UO) and favorable outcome (FO) on the first assessment ( $n=50$ - Left Panel). The area under the receiver operating characteristic (ROC) for $\mathrm{CVH} / \mathrm{ICC}$ 
score to predict UO is shown on the Right Panel.
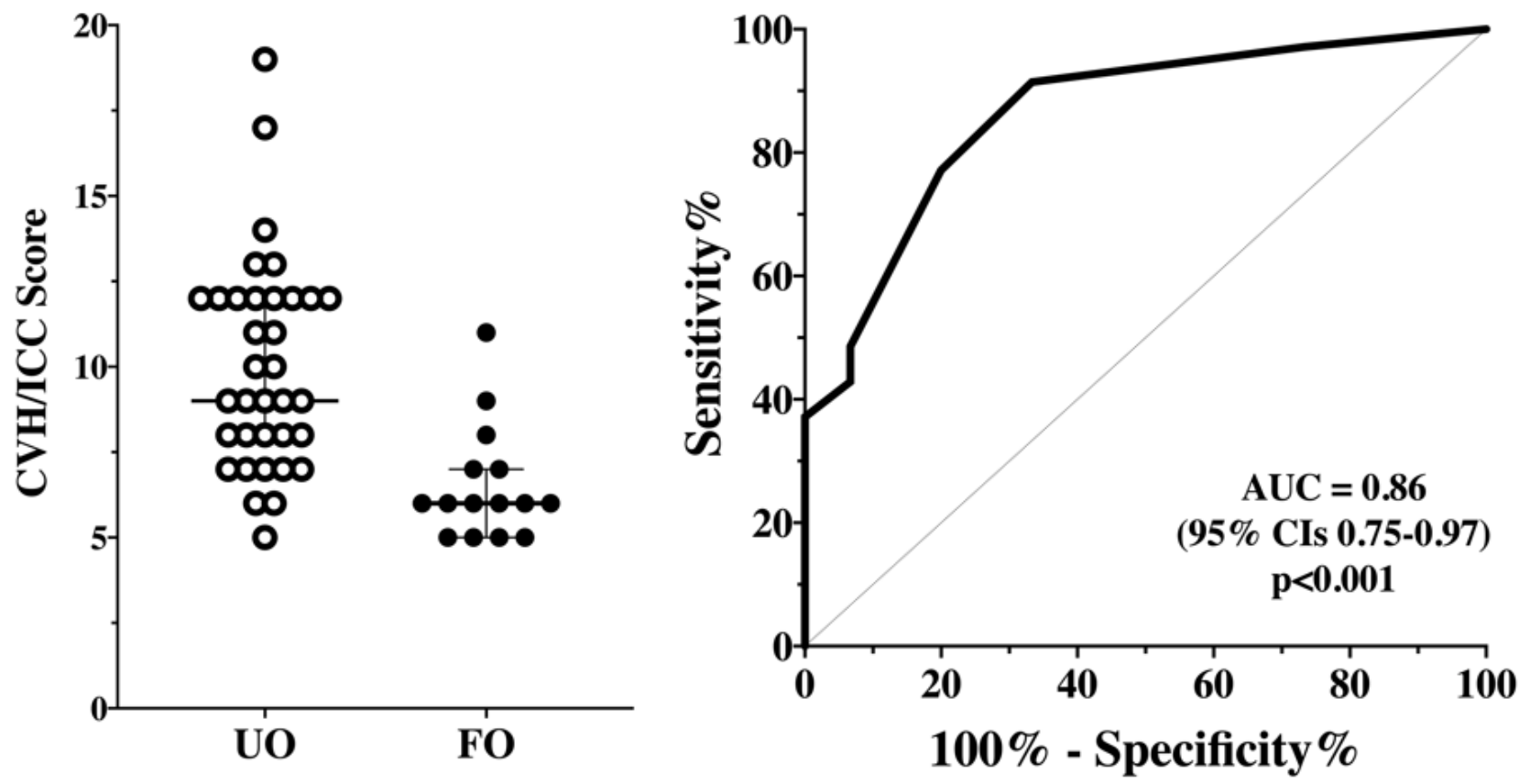

Figure 3

CVH/ICC score between patient with unfavorable (UO) and favorable outcome (FO) on the first assessment ( $n=50$ - Left Panel). The area under the receiver operating characteristic (ROC) for CVH/ICC score to predict UO is shown on the Right Panel.

\section{Supplementary Files}

This is a list of supplementary files associated with this preprint. Click to download.

- STARD.docx

- STARD.docx

- STARD.docx 